\title{
Self-Reported Sedative Drug Use Among Students Attending at University of Gondar, Gondar, Northwest, Ethiopia: A Cross-Sectional Study
}

\section{Gashaw Binega Mekonnen (D' Simachew Gidey Debeb (iD ${ }^{1}$ Nurahmed Seid Getaw ${ }^{2}{ }^{2}$ Zemene Demelash Kifle $\mathbb{D D}^{3}$}

'Department of Clinical Pharmacy, School of Pharmacy, College of Medicine and Health Sciences, University of Gondar, Gondar, Ethiopia; ${ }^{2}$ Department of Pharmaceutical Analysis, School of Pharmacy, College of Medicine and Health Sciences, University of Gondar, Gondar, Ethiopia; ${ }^{3}$ Department of Pharmacology, School of Pharmacy, College of Medicine and Health Sciences, University of Gondar, Gondar, Ethiopia
Correspondence: Simachew Gidey Debeb University of Gondar, College of Medicine and Health Sciences, School of Pharmacy, Department of Clinical Pharmacy, P.O. Box: 196, Gondar, Ethiopia Email simachewgidey4@gmail.com
Background: Medical students experience significant psychological stress and are therefore at higher risk of using sedatives. There are currently no studies describing the prevalence of sedative drug use among medical students in Ethiopia. This study aimed to assess the prevalence and associated factors of self-reported sedative drug use among medical students attending the College of Medicine and Health Science (CMHS) students at the University of Gondar (UoG).

Material and Methods: A prospective cross-sectional study was conducted from May to July 2018 in CMHS at UoG. Data were collected using a pre-tested self-administered standard questionnaire. Data were collected, entered into a computer using Epi Info 7 software, and analyzed using SPSS version 20. Frequency, mean, and standard deviation were used to describe descriptive statistics, and binary and multiple logistic regression analyses were used to assess the association between different variables and sedative drug use; $P<0.05$ was used to declare association.

Results: Of the 422 students who returned questionnaires, 26 (6.2\%) participants were reported sedative drug use at some time since enrollment. Of these, $61.54 \%$ participants used antihistamine drugs. Smoking status (AOR (95\% CI), $0.046(0.009-0.241) P=0.0001)$, stimulant use (AOR (95\% CI), $0.220(0.062-0.780) P=0.019)$, sleeping hour (AOR $(95 \%$ CI), 9.931 (4.155-14.785) $P=0.001)$ and sleep disorder (AOR (95\% CI), 0.149 (0.0330.680) $P=0.014$ ) were significantly associated with sedative drug use.

Conclusion: Self-reported sedative drug use among medical students at the University of Gondar is relatively low, and antihistamines are the most commonly used drugs. Smoking, stimulant use, sleeping hour, and the presence of sleep disorders were associated with sedative drug use.

Keywords: sedative drug, medical student, University of Gondar, Ethiopia

\section{Background}

It is extensively agreed that drug use and its consequences correspond to a key public health crisis among the young community globally. ${ }^{1,2}$ Medical students face significant psychological stress, and as a result, they are at increased risk of using sedatives. $^{3-5}$ The Sedative medication can be prepared in different strengths and is commonly administered orally as a pill, capsule, or liquid. ${ }^{6}$ Sedatives are taken by some people to augment the outcome of alcohol or opioids. ${ }^{7,8}$ This day the tendency of students toward drugs is the most dangerous. Social and family factors play a significant role in addiction and drug abuse. $1,9,10$ 
Psychological symptoms of stress take account of circumstances such as depression, anxiety, and burnout. ${ }^{11}$ Students follow different approaches, such as cognitive responses, stress management methods, improved assertiveness skills, time management techniques, and counseling sessions, to manage stress. ${ }^{12}$ Nevertheless, unsuitable reactions may happen, such as an augmented risk of sedative drug usage, to minimize the sign of stress or to deal with mental health issues including sleep. ${ }^{13-17}$ The use of sedative drugs by medical students can bring several unwanted outcomes such as causing excessive sleepiness, poor physical coordination, unable to concentrate, giddiness, and sluggishness. ${ }^{18}$

According to the National Drug-Related Deaths Index, benzodiazepines were the most common drug group involved in deaths involving more than one drug (polydrug). ${ }^{19}$ Diazepam (a benzodiazepine) was the most common single prescription drug, implicated in one-third (32\%) of all poisoning deaths. ${ }^{20} \mathrm{~A}$ study conducted in Turkey showed that benzodiazepines (alprazolam, diazepam) were the most frequently used sedative-hypnotics. ${ }^{21}$ Sedative drug use by medical students has been investigated in different countries. A study in the US showed that about $78 \%$ of medical students had used sedative drugs. ${ }^{22}$ Similarly, a study in Turkish reported that $22 \%$ of junior students, $20 \%$ of senior students, and $9 \%$ of residents used sedative drugs. ${ }^{21}$ A study conducted on Saud University medical students showed that there were significant associations between sedative drug use and academic year, regular exercise, hours of sleep per day, and sleep disorders. However, no significant associations were found between sedative drug use and gender, family income, place of residence, smoking, stimulant use during an examination or non-examination times, or sleep pattern. ${ }^{3}$

The use of sedative-hypnotics is frequently associated with adverse effects, and there is many a times loss of the normal sleep architecture. This causes problems both during drug intake and with the withdrawal of drugs. Hence, the need for today is the use of sedative-hypnotics with minimum alteration in sleep architecture. ${ }^{23,24}$

A study conducted in the United States showed that more than $70 \%$ of college students had some degree of sleep-related concerns, and only $11 \%$ of a sample of US college undergraduate students $(\mathrm{N}=191)$ had good sleep quality. ${ }^{25}$ Factors contributing to erratic sleep patterns and poor sleep quality include academic demands, repeated prolonged exposure to light at the wrong time of day because of all-night study sessions and late-night computer work, social interaction with peers, and worrying while falling asleep. ${ }^{25}$ A study done in Saudi Arabia indicated that 124 students $(17.0 \%)$ were defined as sedative drug users (63 males, 61 females). The respondents were distributed over different academic years, with 308 (42.2\%) students in the 1st and 2nd years (preclinical), 208 (28.5\%) students in the 3rd year (mixed preclinical and clinical), and $213(29.3 \%)$ students in the 4th and 5th years. ${ }^{3}$ An additional important point about sedative drug use among medical students was reported by Bennett and O'Donovan, they revealed that sedative drug use might be a way to keep work feat and evade sick leave. ${ }^{26}$

There is a wide range of utilization of sedative drugs in the world. ${ }^{27,28}$ Due to the wide use of these sedative drugs many medical students have been addicted to sedative drugs like benzodiazepine. ${ }^{29-31}$ Furthermore, there is no evidence about the utilization and the size of the problem of sedative drug use in Ethiopia. This study aimed to assess the prevalence and associated factors of selfreported sedative drug use among medical students at the University of Gondar, Northwest Ethiopia.

\section{Method and Materials Study Design, Area, and Period}

An institutional-based cross-sectional study design was conducted at the University of Gondar, Gondar, Ethiopia. University of Gondar is one of the oldest higher education institutions in Ethiopia. It was established in 1954 E.C and is located in the Central Gondar administrative zone, Amhara National Regional State, which is about $750 \mathrm{~km}$ far from Addis Ababa, which is the capital city of Ethiopia. The University of Gondar offers 56 undergraduate and 64 postgraduate programs and the study was conducted on all medical students attending in medicine regular program except those students with serious mental illness. The study was conducted from May-July 2019 at the University of Gondar, Gondar, Ethiopia.

\section{Study Population, Sample Size Determination, and Sampling Technique}

The source population consisted of all medical students attending the College of Medicine and Health Science at the University of Gondar, whereas the study population was all medical students, including from 1 st year to 5 th year.

A single population proportion formula was used to estimate the sample size. Since there was no similar study 
done in Ethiopia, the following assumptions have been made: $95 \%$ confidence interval $(\mathrm{Z} \alpha / 2=1.96$ ), 50\% proportion, and $5 \%$ margin of error. The sample was composed of 422 students from different batches, who were selected using stratified random sampling technique $(\mathrm{k}=4)$.

$$
\begin{gathered}
\mathrm{n}=\frac{\mathrm{z}^{2} \times \mathrm{p}(1-\mathrm{p})}{\mathrm{w}^{2}} \\
\mathrm{n}=\frac{(1.96)^{2} \times 0.5 \times 0.5=384}{(0.05)^{2}}
\end{gathered}
$$

Finally, with the addition of $10 \%$ non-response, a total of 422 participants were included.

\section{Inclusion and Exclusion Criteria}

All from 1st to 5th-year medical students attending at College of Medicine and Health Science, University of Gondar, were included in the study. Those participants with serious mental illness were excluded from studies in order to protect their rights as well as to prevent exposure to disproportionate burden and risk and also to obtain correct data. Subjects who were not willing to give consent were also excluded from the study.

\section{Ethical Considerations}

The research protocol, including informed consent procedures, received full ethical review and approval from the ethical committee of the school of pharmacy, University of Gondar. The research complied with the Helsinki Declaration. All the study participants were announced about the purpose of the study and finally, verbal consent was obtained before data collection. The respondents had the right to refuse participation or terminate their involvement at any time to the study. The information provided by each respondent is kept confidential.

\section{Study Variables}

The dependent variable was sedative drug use among medical students in CMHS, whereas the independent variables were age, gender, academic year, average monthly family income, smoking, exercise, and stimulant use.

\section{Definition of Terms and Operational Definition}

Sedative: Allaying irritability or excitement, assuaging pain, lowering functional activity. Antihistamine: Those drugs which are capable of diminishing or preventing several pharmacological effects of histamine.
Benzodiazepine: Any family minor tranquilizers that act against anxiety and convulsions produce sedation and relaxation.

Barbiturate: Any class of sedatives and sleep inducers from barbituric acid.

Stimulant: Substance that raises the level of physiological or nervous activity.

Sleep disorder: Any disorder that affects disrupts or involves sleep.

\section{Data Collection Tools}

The questionnaire was developed by the authors, and data was collected using a pre-tested self-administered structured questionnaire. Data were collected by all the investigators, and data collectors were trained for two days by the advisors to ensure the quality of data collection. They were given an orientation on the protocol and specific details concerning participation in the study. Before study commencement, they were carrying out practice sessions with authentic respondents. These preliminary interviews, review patient recorders observed and reviewed by the principal investigator.

\section{Data Quality Control}

To ensure the quality of data, the questionnaires were developed in English and translated into Amharic. A Pretest was done on 5\% (20) selected medical students in Bahir Dar university to make sure that whether the study was feasible in this way and to see if the questioner is appropriate and consistent to gathering the intended information. After that, necessary modifications were applied to the questioner. The quality checking was done daily after data collection, and necessary amendments were made to the next data collection measure. Data cleanup and cross-checking were done before analysis.

\section{Data Analysis}

Data were collected, entered into a computer using Epi Info 7 software, and analyzed using SPSS version 20. Frequency, mean, and standard deviation were used to describe descriptive statistics, and binary and multiple logistic regression analyses were used to assess the association between different variables and sedative drug use. The independent variables (sex, age, monthly income, smoking, use of stimulant, sleep hours, and sleep disorder) to be contained within the multiple regression model, it must be significantly correlated with sedative drug use in 
Table I Socio-Demographic Characteristics of Medical Students in University of Gondar

\begin{tabular}{|l|l|l|}
\hline \multicolumn{2}{|l|}{ Variables } & Number (\%) \\
\hline Sex & $\begin{array}{l}\text { Male } \\
\text { Female }\end{array}$ & $\begin{array}{l}278(65.9 \%) \\
144(34.1 \%)\end{array}$ \\
\hline Age & $18-20$ & $141(33.4 \%)$ \\
& $2 I-25$ & $224(53.1 \%)$ \\
& Above 25 & $57(13.5 \%)$ \\
\hline Academic year & Ist & $71(16.8 \%)$ \\
& 2 nd & $93(22 \%)$ \\
& $3 r d$ & $99(23.5 \%)$ \\
& 4 th & $103(24.4 \%)$ \\
& 5 th & $56(13.3 \%)$ \\
\hline Family monthly income & $<900$ & $106(25.1 \%)$ \\
& $90 I-3600$ & $188(44.55 \%)$ \\
& $>3600$ & $128(30.35 \%)$ \\
\hline
\end{tabular}

the univariate analysis. Statistical significance was set at $\mathrm{P}$ values of less than 0.05 .

\section{Result}

\section{Socio-Demographic Characteristics}

Out of the total 422 students that participated in the survey, questionnaires from 422 respondents were complete and considered for analysis making the response rate $100 \%$. Of the total 422 respondents 224 (53.1\%) were aged 21-25 years with a mean age of $22.57(\mathrm{SD} \pm 2.46)$ \pm years from the total participants, 278 (65.9\%) were males and 144 (34.1\%) were females. Participants were scattered in diverse academic years, with 71 (16.8\%) students in the 1st yrs, $93(22 \%)$ in the 2 nd yrs, $99(23.5 \%)$ in the 3rd yrs, $103(24.4 \%)$ in the 4th, and $56(13.3 \%)$ in the 5 th years (Table 1$)$.

\section{Prevalence of Sedative Drug Use}

Out of 422 respondents invited to participate, $43(10.2 \%)$ of them were smokers, and about 165 (39.1\%) of the students were reported to use stimulants during an exam and at any time. Among the participants, 26 $(6.2 \%)$ were defined as sedative drug users (23 males, 3 females). Respondents were distributed over different academic years. Among them, first-year and secondyear students were the same frequency and most of the sedative drug users were above 3 years of the academic year. Half of the respondents who reported using sedative drug type used antihistamines. Antihistamines were prescribed to 16 students $(61.54 \%)$ who reported usage, while the remaining $10(38.46 \%)$ students used Benzodiazepines and Barbiturates. Among the percipients, $19.4 \%$ were defined as alcohol users and $60.9 \%$ were not using stimulants and the remaining $39.1 \%$ were defined as use stimulants during an exam and at any time. Eighty-two (19.4\%)students used alcohol as a sedative, and 18 (69.23\%) respondents experienced anxiety and depression during sedative drug use (Table 2).

\section{Factors Associated with Sedative Drug Use}

Initially, different variables such as age, gender, median family income, academic year, smoking, use of a stimulant, sleep hour, sleep disorder, sleep pattern, and regular exercise were considered for univariate analysis. In the univariate analysis, the following variables showed a statistically significant association with sedative use: smoking, sleep disorder, gender, use of a stimulant, age, median family income, academic year, and sleep hour. These variables were taken and analyzed together using a multivariate logistic regression model. After controlling for the effects of potentially confounding variables using a multivariate logistic regression model, smoking, median family income, use of a stimulant, sleep disorder, and sleep hours were found to be statistically significant predictors of sedative drug use.

Sedative drug use was less common among nonsmokers than smokers $(2.90 \%$ versus $34.88 \%)$. As compared to being a smoker, being a non-smoker reduces the magnitude of sedative drug use by $4.6 \%$ (AOR (95\% CI), 0.063 (0.014-0.280) $P=0.0001)$. Individuals who did not take any stimulants had less commonly used sedative drugs than stimulant users $(2.72 \%$ versus $11.52 \%)$. Being non-stimulant user reduces the magnitude of sedative drug use by $22 \%$ (AOR (95\% CI), 0.176 (0.051-0.613) $P=0.006)$. Sedative drug use was less common among students whose median family income is 901-3600 birr ((freq. 1.06\%) (AOR (95\% CI), $0.021(0.003-0.156) P=$ $0.0001)$ than students whose median family income is $>3600$ birr (frequency of $12.50 \%$ ). Sedative drug use was also more common among students who slept for less than 4 hours per day than those who slept for greater than 8 hours per day (38.46\% versus $9.09 \%)$. Students who slept less than 4 hours per day were 39.93 times more likely to use sedative drugs as compared to those who slept greater than 8 hours per day (AOR (95\% CI), 
Table 2 Prevalence of Sedative Drug Use Among Medical Students in University of Gondar

\begin{tabular}{|c|c|c|}
\hline Variable & $\begin{array}{l}\text { Frequency } \\
\text { (N) }\end{array}$ & $\begin{array}{l}\text { Percent } \\
\text { (\%) }\end{array}$ \\
\hline Smoking & 422 & \\
\hline Yes & 43 & 10.2 \\
\hline No & 379 & 89.8 \\
\hline Exercise & 422 & \\
\hline Yes & 55 & 13.0 \\
\hline No & 367 & 87.0 \\
\hline Use of stimulant & 422 & \\
\hline No & 257 & 60.9 \\
\hline Yes & 165 & 39.1 \\
\hline Time of use stimulant & 165 & \\
\hline During exam & 157 & 95.2 \\
\hline At any time & 8 & 4.9 \\
\hline Sleep hours & 422 & \\
\hline$<4$ hrs & 13 & 3.1 \\
\hline 4-6 hrs & 219 & 51.9 \\
\hline $7-8 \mathrm{hrs}$ & 135 & 32.0 \\
\hline$>8$ & 55 & 13.0 \\
\hline Sleep pattern & 422 & \\
\hline Night & 178 & 42.2 \\
\hline Day & 4 & 0.9 \\
\hline Day and night & 240 & 56.9 \\
\hline Sleep disorder & 422 & \\
\hline Yes & 53 & 12.6 \\
\hline No & 369 & 87.4 \\
\hline Sedative drug use & 422 & \\
\hline Yes & 26 & 6.2 \\
\hline No & 396 & 93.8 \\
\hline Types of sedative drug use & 26 & \\
\hline Antihistamines & 16 & 61.5 \\
\hline Chlorpheniramine & 8 & 50 \\
\hline Dexchlopheniramine & 0 & 0 \\
\hline Dimenhydrinte & 0 & 0 \\
\hline Diphenhydramine & 0 & 0 \\
\hline Promethazine & 8 & 50 \\
\hline Benzodiazepam & 4 & 15.4 \\
\hline Diazepam & 4 & 100 \\
\hline Chlordiazepoxide & 0 & 0 \\
\hline Lorazepam & 0 & 0 \\
\hline Clonazepam & 0 & 0 \\
\hline Barbiturates & 6 & 23.1 \\
\hline Phenobarbital & 6 & 100 \\
\hline Thiopental & 0 & 0 \\
\hline
\end{tabular}

(Continued)
Table 2 (Continued).

\begin{tabular}{|c|l|l|}
\hline Variable & $\begin{array}{l}\text { Frequency } \\
\text { (N) }\end{array}$ & $\begin{array}{l}\text { Percent } \\
\text { (\%) }\end{array}$ \\
\hline $\begin{array}{l}\text { How would you get the medication } \\
\text { With prescription }\end{array}$ & 26 & \\
Without prescription & 11 & 42.3 \\
& 15 & 57.7 \\
\hline Duration of sedative Drug use & 26 & \\
Frequently & 7 & 26.9 \\
Sometimes & 9 & 34.6 \\
Occasionally & 10 & 38.5 \\
\hline $\begin{array}{l}\text { Did you experience anxiety and } \\
\text { depression during sedative use } \\
\text { Yes }\end{array}$ & $\mathbf{2 6}$ & \\
No & 18 & 69.2 \\
\hline Use of alcohol as sedative & 8 & 30.8 \\
Yes & 422 & \\
No & 82 & 19.4 \\
\hline
\end{tabular}

9.989 (4.646-14.188) $P=0.001)$. Sedative drug use was less common among students who did not report sleeping disorders than those who reported sleeping disorders (2.98\% versus $28.30 \%)$. Having no sleep disorder reduces the magnitude of sedative drug use by $14.9 \%$ $\left(\begin{array}{llllll}\text { AOR } & (95 \% & \text { CI }), & 0.131 & (0.029-0.599) & P=0.009\end{array}\right)$ (Table 3).

\section{Discussion}

Sedative drug use among medical students varies between countries depending on differences in culture and availability. ${ }^{3,24,32}$ To our knowledge, this is the first study conducted to assess the prevalence and associated factors with sedative drug use among medical students in Ethiopia.

In the present study, the mean age of the respondents was $22.57 \pm 2.46$ years, comparable to the mean age confirmed by Bethany et al $2013 .{ }^{33,34}$ In this study, the prevalence of sedative drug use was $6.2 \%$. This finding is lower than the studies conducted in King Saud University, the prevalence of sedative drug use was $17.0 \%,{ }^{3}$ in the Republic of Macedonia it was found to be $12 \%,{ }^{35}$ and in Iran, the prevalence of sedative drug use was $7.4 \% .{ }^{36}$ The observed differences might be due to the difference in the methodology, study area, socio-cultural characteristics of the participants, easy availability and accessibility of 
Table 3 Factors Associated with Sedative Drug Use Among Medical Students in University of Gondar

\begin{tabular}{|c|c|c|c|c|c|c|}
\hline \multicolumn{2}{|l|}{ Variable } & \multicolumn{2}{|c|}{ Sedative Drug Use } & \multicolumn{2}{|l|}{ OR with $95 \%$ C.I. } & \multirow{3}{*}{$\begin{array}{l}\text { P-value } \\
\\
0.785\end{array}$} \\
\hline & & Yes & No & Crude & Adjusted & \\
\hline Sex & $\begin{array}{l}\text { Female } \\
\text { Male }\end{array}$ & $\begin{array}{l}3 \\
23\end{array}$ & $\begin{array}{l}14 \mid \\
255\end{array}$ & $\begin{array}{l}0.236(0.070-0.799) \\
\text { I }\end{array}$ & $\begin{array}{l}0.809(0.176-3.720) \\
\text { I }\end{array}$ & \\
\hline Age & $\begin{array}{l}18-20 \\
21-25 \\
>25\end{array}$ & $\begin{array}{l}3 \\
16 \\
7\end{array}$ & $\begin{array}{l}138 \\
208 \\
50\end{array}$ & $\begin{array}{l}0.155(0.039-0.624) \\
0.549(0.215-1.407) \\
\text { । }\end{array}$ & $\begin{array}{l}2.131(0.312-14.556) \\
2.353(0.559-9.894) \\
।\end{array}$ & $\begin{array}{l}0.440 \\
0.243\end{array}$ \\
\hline Median monthly income & $\begin{array}{l}\leq 900 \\
901-3600 \\
>3600\end{array}$ & $\begin{array}{l}8 \\
2 \\
16\end{array}$ & $\begin{array}{l}98 \\
186 \\
112\end{array}$ & $\begin{array}{l}0.57 \mid(0.234-1.393) \\
0.075(0.017-0.333) \\
I\end{array}$ & $\begin{array}{l}0.350(0.100-1.223) \\
0.021(0.003-0.156) \\
I\end{array}$ & $\begin{array}{l}0.100 \\
0.0001\end{array}$ \\
\hline Smoking & $\begin{array}{l}\text { No } \\
\text { Yes }\end{array}$ & $\begin{array}{l}11 \\
15\end{array}$ & $\begin{array}{l}368 \\
28\end{array}$ & $\begin{array}{l}0.056(0.023-0.133) \\
\text { I }\end{array}$ & $\begin{array}{l}0.063(0.014-0.280) \\
\text { I }\end{array}$ & 0.0001 \\
\hline Use of stimulant & $\begin{array}{l}\text { No } \\
\text { Yes }\end{array}$ & $\begin{array}{l}7 \\
19\end{array}$ & $\begin{array}{l}250 \\
146\end{array}$ & $\begin{array}{l}0.215(0.088-0.524) \\
I\end{array}$ & $\begin{array}{l}0.176(0.051-0.613) \\
I\end{array}$ & 0.006 \\
\hline Sleep hours & $\begin{array}{l}<4 \text { hours } \\
4 \text { to } 6 \text { hours } \\
7 \text { to } 8 \text { hours } \\
>8\end{array}$ & $\begin{array}{l}5 \\
12 \\
4 \\
5\end{array}$ & $\begin{array}{l}8 \\
207 \\
131 \\
50\end{array}$ & $\begin{array}{l}6.250(1.47-26.56) \\
0.580(0.19,1.72) \\
0.305(0.078,1.18) \\
1\end{array}$ & $\begin{array}{l}9.989(4.646-14.188) \\
4.635(0.858-25.044) \\
0.928(0.149-5.780) \\
I\end{array}$ & $\begin{array}{l}0.001 \\
0.075 \\
0.936\end{array}$ \\
\hline Sleep disorder & $\begin{array}{l}\text { No } \\
\text { Yes }\end{array}$ & $\begin{array}{l}11 \\
15\end{array}$ & $\begin{array}{l}358 \\
38\end{array}$ & $\begin{array}{l}0.078(0.033-0.182) \\
1\end{array}$ & $\begin{array}{l}0.13 \mathrm{I}(0.029-0.599) \\
\mathrm{I}\end{array}$ & 0.009 \\
\hline
\end{tabular}

Abbreviations: OR, odds ratio; $\mathrm{Cl}$, confidence interval.

sedative drugs, social acceptability of sedative drug use, and the numbers and types of drugs included in the study.

Medical students may experience considerable anxiety and depression, which may result in the use of sedative drugs. ${ }^{14,16,37}$ In this study, the experience of anxiety and depression during sedative use was $69.23 \%$. This result is lower than similar studies in King Republic of Macedonia $75.9 \% .{ }^{35}$ But, higher than the previous study done in Saudi Arabia medical students and reported that $66.6 \%$ of female students and $44.4 \%$ of male students experienced anxiety and depression. ${ }^{38}$ This difference may instigate from tough schoolwork, being dispassionate in their field of study, extended years of study, and due to the way they got and interpersonal variability. So, addressing the stressors of medical education and the student environment appears to reduce sedative drug use and get better abstinence rates.

The prevalence of alcohol use was $19.2 \%$. This finding is lower than the studies done in the Republic of Macedonia medical students, ${ }^{35}$ and Saudi university students. ${ }^{39}$ Likewise, a study conducted in Ethiopia showed that $50.2 \%$ of the participants drank alcohol at least once in their lifetime. ${ }^{40}$ This difference might be due to there are strong rules and regulations and a good study environment in the study area (Gondar University). However, the present finding is higher than the study conducted by Karam et al, who found that the alcohol prevalence was $10.5 \%,{ }^{41}$ and $10.29 \%$ in Zagazig University Students. ${ }^{34}$ This difference might be due to homemade alcoholic drinks are acceptable for the vast majority of Ethiopian people.

A study conducted in the Zagazig University revealed that the smoking prevalence was found to be $26.1 \%$ in males and $1.4 \%$ in females. ${ }^{34}$ Findings reported by Loffredo et al revealed that the smoking prevalence in males was $27.5 \%$ and $18.1 \%$ in females. ${ }^{42}$ Similarly, a study conducted in Egypt showed that the smoking prevalence was $16.81 \%{ }^{43}$ and $14.5 \%$ in Saudi University students. ${ }^{39}$ In the present study, the lifetime prevalence of cigarette smoking was $10.2 \%$, which is lower than the above findings. This difference might be due to there are strong rules and regulations at the University of Gondar, and because of the cultural and social traditions in Ethiopia. According to the current findings, non-smoker students $(2.90 \%$ versus $34.88 \%$ ) (AOR (95\% CI), 0.063 $(0.014-0.280) P$-value $=0.0001)$ were less likely to use sedative drugs than smokers. However, a study on Saudi 
university medical students was not significant. ${ }^{3}$ This difference might be due to the study area and sample size.

Among the sedative drug users, $61.54 \%$ used antihistamine drugs. So, the most abused sedative drugs were antihistamines followed by barbiturates then benzodiazepines. These were in an agreement with studies conducted in King Saud University Medical Students, ${ }^{3}$ and a University Hospital in Saudi Arabia. ${ }^{44}$ However, a study conducted in Turkey showed that benzodiazepines are the most commonly used sedative drugs among students. ${ }^{21}$ This may be due to first-generation antihistamines are easily available as over-the-counter medications, and many people use them as sleeping aids.

Benzodiazepines and barbiturates are merely obtainable as a sleep induction in hospitals and were not allowed to be prescribed for this use in nonhospitalized patients. ${ }^{45}$ Use of such class of drug for other grounds is cautiously restricted, including prescriptions for mentally ill patients, which are merely rational when there is hospital admission. However, antihistamines are easily obtainable as OTC medications, and a lot of communities were used to induce sleep. ${ }^{44}$ Medical students misuse sedative drugs, which can potentially impinge on their health and performance and could cause addiction or dependence. ${ }^{18}$ In the current study, $57.7 \%$ of the respondents got the sedative drugs without prescription, and $42.3 \%$ of the respondents got the medications with prescription. Sedative drug use by medical students can influence their capacity to concentrate and resulting in extreme sleepiness, sluggishness, giddiness, and poor physical coordination.

Students reporting sleep disorders such as insomnia were more likely to use sedative drugs. ${ }^{46,47}$ In this study, sedative drug use was more common among students who slept for less than 4 hours per day (38.46\% versus $9.09 \%)$ (AOR (95\% CI), 9.989 (4.646-14.188) $P=0.001$ ) than those who slept for greater than 8 hours per day, and this association strongly supported by a study conducted in Saudi university AOR (95\% CI), $1.743(1.122-2.705 P=$ $0.0013)$. In the current study, sedative drug use was less common among students who did not report sleeping disorders than those who reported sleeping disorders $(2.98 \%$ versus $28.30 \%$ ) (AOR (95\% CI), $0.131(0.029-0.599) P=$ $0.009)$. This association also supported by a study conducted in Saudi university AOR $(95 \%$ CI) 0.288 (0.1920.432) $P<0.001 .^{3}$ This may be due to students who did not get many hours of sleep may not have been as good at organizing their time and their sleep-wake cycles and may therefore have been more likely to use sedative drugs to induce sleep.

Among students who were use stimulants, $4.85 \%$ of them were used at any time. This result is much lower than the study done among medical students in King Saud University $(17.7 \%){ }^{3}$ and in the United States $(9.7 \%){ }^{48}$ However, it is higher than the study conducted in Zagazig University (4\%), ${ }^{34}$ and the study done by Allah et al. ${ }^{49}$ In the current study, Individuals who did not take any stimulants had less commonly used sedative drugs than stimulant users (2.72\% versus $11.52 \%)$ (AOR $(95 \% \mathrm{CI}), 0.176$ (0.051-0.613) $P=0.006)$. However, a study on Saudi university medical students was not significant. ${ }^{3}$ This difference might be due to the study area, sample size, environmental and social dimensions, disparity in attitudes, and legislations and rules of dispensing of medicines in the community and hospital pharmacies.

Studies have shown that there is an association between family socioeconomic status and substance use. ${ }^{50}$ Family support is correlated to the use of a variety of sedative drugs, particularly in women, because as supposed family support exacerbates, the percentage of the community who have tried drugs increases. ${ }^{51}$ In this study, sedative drug use was less common among students whose median family income is $901-3600$ birr (freq. $1.06 \%$ (AOR $(95 \% \mathrm{CI}$ ), $0.021(0.003-0.156) P=0.0001)$ than students whose median family income is $>3600$ birr (frequency of $12.50 \%$ ). However, a study reported in the USA showed that those who came from low-income families had a superior likelihood of sedative drug users (AOR (95\% CI), 1.52 (1.181.96)). Some of the justification presented to such association were that students from low-income families may have fewer admission to suitable medical notice or direction on sedative drug use. Additionally, low-income families may pressure students' drug use by resulting in parents' emotional suffering, which then results in parental disagreement and a deprived parenting approach. ${ }^{52}$ Unlike the current findings, a study in Saudi university medical students revealed that no significant associations were found between sedative drug use and family income. ${ }^{3}$ This difference might be due to socioeconomic characteristics and sample size.

As a limitation, the accuracy of responses on the selfreporting questionnaires may have been adversely affected by the respondents' inability or unwillingness to provide the requested information. The present study relied on self-report, which is the limitation of the current study, so other methods should be used in future studies to evaluate sedative drug use. Nevertheless, this study has 
widespread implications for the promotion of rational sedative drug use.

\section{Conclusions and Recommendation}

Self-reported sedative drug use among medical students at the University of Gondar is relatively low. The most commonly used sedative drugs among students were antihistamines. Smoking, sleeping hour, and the presence of sleeping disorders were significantly associated with sedative drug use. Further understanding of sedative drug use and the factors associated with increased use is helpful for the development of early intervention programs for medical students, who are a high-risk population facing a stressful future career path. Universities should provide sessions regarding sedative drug use in educational settings, and create training centers concerning sedative drug use.

\section{Data Sharing Statement}

The data sets supporting the finding of this study can be obtained from the corresponding author upon request.

\section{Acknowledgment}

The authors acknowledge the support of the School of Pharmacy, University of Gondar in facilitating the data collection process. We are also grateful to all the participants of the study.

\section{Funding}

There is no funding to report.

\section{Disclosure}

The authors declare that they have no conflict of interest.

\section{References}

1. Le Bon O, Basiaux P, Streel E, et al. Personality profile and drug of choice; a multivariate analysis using Cloninger's TCI on heroin addicts, alcoholics, and a random population group. Drug Alcohol Depend. 2004;73(2):175-182. doi:10.1016/j.drugalcdep.2003.10.006

2. Rhodes T, Stimson GV, Fitch C, Ball A, Renton A. Rapid assessment, injecting drug use, and public health. Lancet. 1999;354(9172):65-68. doi:10.1016/S0140-6736(98)07612-0

3. Al-Sayed AA, Al-Rashoudi AH, Al-Eisa AA, et al. Sedative drug use among King Saud University medical students: a cross-sectional sampling study. Depress Res Treat. 2014;2014:1-7. doi:10.1155/2014/ 378738

4. Pourghaznein T, Salati S, Jamali J, Rangani F, Khazaei E. Study of behaviors and psychological indicators in Iranian medical students during the COVID-19 pandemic self-quarantine. J Health Lit. 2021;6 (1):61-71.
5. Fawzy M, Hamed SA. Prevalence of psychological stress, depression and anxiety among medical students in Egypt. Psychiatry Res. 2017;255:186-194. doi:10.1016/j.psychres.2017.05.027

6. Stubbs J, Haw C, Dickens G. Dose form modification-a common but potentially hazardous practice. A literature review and study of medication administration to older psychiatric inpatients. Int Psychogeriatr. 2008;20(3):616-627. doi:10.1017/ S1041610207006047

7. Tobias JD, Leder M. Procedural sedation: a review of sedative agents, monitoring, and management of complications. Saudi J Anaesth. 2011;5(4):395. doi:10.4103/1658-354X.87270

8. Donaldson M, Gizzarelli G, Chanpong B. Oral sedation: a primer on anxiolysis for the adult patient. Anesth Prog. 2007;54(3):118-129. doi:10.2344/0003-3006(2007)54[118:OSAPOA]2.0.CO;2

9. Foo Y-C, Tam C-L, Lee T-H. Family factors and peer influence in drug abuse: a study in rehabilitation centre. Int $J$ Collab Res Intern Med Public Health. 2012;4(3).

10. Park SK, Kim JY, Cho CB. Prevalence of internet addiction and correlations with family factors among South Korean adolescents. Adolescence. 2008;43(172):895-909.

11. Vandevala T, Pavey L, Chelidoni O, Chang N-F, Creagh-Brown B, Cox A. Psychological rumination and recovery from work in intensive care professionals: associations with stress, burnout, depression and health. J Intensive Care. 2017;5(1):1-8. doi:10.1186/s40560-017-0209-0

12. Chinaveh M, Ishak NM, Salleh AM. Improving mental health and academic performance through multiple stress management intervention: implication for diverse learners. Procedia Soc Behav Sci. 2010;7:311-316. doi:10.1016/j.sbspro.2010.10.043

13. Yiu V. Supporting the well-being of medical students. CMAJ. 2005;172(7):889-890. doi:10.1503/cmaj.050126

14. Dahlin M, Joneborg N, Runeson B. Stress and depression among medical students: a cross-sectional study. Med Edu. 2005;39 (6):594-604. doi:10.1111/j.1365-2929.2005.02176.x

15. Quince TA, Wood DF, Parker RA, Benson J. Prevalence and persistence of depression among undergraduate medical students: a longitudinal study at one UK medical school. BMJ Open. 2012;2 (4):e001519. doi:10.1136/bmjopen-2012-001519

16. Guthrie E, Black D, Bagalkote H, Shaw C, Campbell M, Creed F. Psychological stress and burnout in medical students: a five-year prospective longitudinal study. J R Soc Med. 1998;91(5):237-243. doi: $10.1177 / 014107689809100502$

17. Hamaideh SH. Stressors and reactions to stressors among university students. Int J Soc Psychiatry. 2011;57(1):69-80. doi:10.1177/ 0020764009348442

18. KC Dube AK, Gupta S, Dube F, Kumar SN. Drug use among college students-an interim report. Senior Research Officers, International Pilot Study of Schizophrenia, Mental Hospital, Agra. 1977;47-61.

19. Graham L, Matthews S, Dunbar JK, Stoner N. The National Drug Related Deaths Database (Scotland) Report 2009. Edinburgh: Information Services Divisions; 2010.

20. Moore J. Drugs in focus-policy briefing. Drugnet Ireland. 2012;33:27.

21. Akvardar Y, Demiral Y, Ergor G, Ergor A. Substance use among medical students and physicians in a medical school in Turkey. Soc Psychiatry Psychiatr Epidemiol. 2004;39(6):502-506. doi:10.1007/ s00127-004-0765-1

22. McAuliffe WE, Rohman M, Santangelo S, et al. Psychoactive drug use among practicing physicians and medical students. $N$ Engl J Med. 1986;315(13):805-810. doi:10.1056/NEJM198609253151305

23. Ashish kumar U, Palatty P. Comparative action of sedative hypnotics on neurophysiology of sleep. J Sleep Disord Ther. 2013;2 (150):2167-0277.10001.

24. Dalui SK, Datta A, Ghosh A, Biswas S, Roy UK, Biswas S. Selfmedication of sleeping pills among MBBS students in a medical college of West Bengal, India. Int J Basic Clin Pharmacol. 2017;6 (7):1689-1695. doi:10.18203/2319-2003.ijbcp20172732 
25. ElArab HE, Rabie MA, Ali DH. Sleep behavior and sleep problems among a medical student sample in relation to academic performance: a cross-sectional questionnaire-based study. Middle East Curr Psychiatry. 2014;21(2):72-80. doi:10.1097/01. XME.0000444452.76469.05

26. Bennett J, O'Donovan D. Substance misuse by doctors, nurses and other healthcare workers. Curr Opin Psychiatry. 2001;14 (3):195-199. doi:10.1097/00001504-200105000-00006

27. Schumacher L, Dobrinas M, Tagan D, Sautebin A, Blanc A-L, Widmer N. Prescription of sedative drugs during hospital stay: a Swiss prospective study. Drugs Real World Outcomes. 2017;4 (4):225-234. doi:10.1007/s40801-017-0117-6

28. Roussin A, Bouyssi A, Pouché L, Pourcel L, Lapeyre-Mestre M, Hsiao CK. Misuse and dependence on non-prescription codeine analgesics or sedative $\mathrm{H} 1$ antihistamines by adults: a cross-sectional investigation in France. PLoS One. 2013;8(10):e76499. doi:10.1371/ journal.pone.0076499

29. Weaver MF. Focus: addiction: prescription sedative misuse and abuse. Yale J Biol Med. 2015;88(3):247.

30. Salzman C. Addiction to benzodiazepines. Psychiatr Q. 1998;69 (4):251-261. doi:10.1023/A:1022125929946

31. Konopka A, Pełka-Wysiecka J, Grzywacz A, Samochowiec J. Psychosocial characteristics of benzodiazepine addicts compared to not addicted benzodiazepine users. Prog Neuropsychopharmacol Biol Psychiatry. 2013;40:229-235. doi:10.1016/j.pnpbp.2012.09.001

32. Jirbi TS. Prevalence and pattern of drug abuse among medical students at the college of medical sciences, University of Maiduguri. Fac Psychiatry. 2005.

33. Bethany BK, Rodolico J, Hill KP. Sex, age, and progression of drug use in adolescents admitted for substance use disorder treatment in the northeastern United States: comparison with a national survey. Subst Abuse. 2013;34(3):263-272. doi:10.1080/08897077.2013.770424

34. Amin DM, Elnagdi SA, Amer SA. Drug abuse in Zagazig University Students, Egypt: Cross Sectional Study, 2018. Occup Dis Environ Med. 2019;7(02):37. doi:10.4236/odem.2019.72004

35. Mancevska S, Pluncevic JP, Todorovska L, Dejanova B, Tecce J. Substance use and perceived hassles among junior medical students with high anxiety levels in the Republic of Macedonia. Iran J Public Health. 2014;43(10):1451.

36. Rezahosseini O, Roohbakhsh A, Tavakolian V, Assar S. Drug abuse among University students of Rafsanjan, Iran. Iran J Psychiatry Behav Sci. 2014;8(2):81.

37. Dyrbye LN, Thomas MR, Shanafelt TD. Medical student distress: causes, consequences, and proposed solutions. Paper presented at: Mayo Clinic Proceedings; 2005.

38. El-Rufaie O, Albar A, Al-Dabal B. Identifying anxiety and depressive disorders among primary care patients: a pilot study. Acta Psychiatr Scand. 1988;77(3):280-282. doi:10.1111/j.16000447.1988.tb05121.x
39. Mandil A, Bin Saeed A, Dabbagh R, Shaikh S, Al Saadi M, Khan M. Smoking among Saudi University students: consumption patterns and risk factors. East Mediterr Health J. 2011;17(4):309-316. doi:10.26719/2011.17.4.309

40. Refaat A. Practice and awareness of health risk behaviour among Egyptian university students. EMHJ-Eastern Mediterranean Health Journal. 2004;10(1-2):72-81.

41. Karam E, Kypri K, Salamoun M. Alcohol use among college students: an international perspective. Curr Opin Psychiatry. 2007;20 (3):213-221. doi:10.1097/YCO.0b013e3280fa836c

42. Adams ML, Jason LA, Pokorny S, Hunt Y. The relationship between school policies and youth tobacco use. J Sch Health. 2009;79 (1):17-23. doi:10.1111/j.1746-1561.2008.00369.x

43. Loffredo CA, Radwan GN, Eltahlawy EM, El-Setouhy M, Magder L, Hussein MH. Estimates of the prevalence of tobacco smoking in Egypt. Open J Epidemiol. 2015;5(02):129. doi:10.4236/ ojepi.2015.52017

44. Al-Sabaie AS, Abdul-Rahim F-A, Oni GA, Hawari RA. The use of sedative-hypnotic drugs in a university hospital in Saudi Arabia. Ann Saudi Med. 1994;14(5):379-382. doi:10.5144/0256-4947.1994.379

45. Dell'osso B, Lader M. Do benzodiazepines still deserve a major role in the treatment of psychiatric disorders? A critical reappraisal. Eur Psychiatry. 2013;28(1):7-20. doi:10.1016/j.eurpsy.2011.11.003

46. Azad MC, Fraser K, Rumana N, et al. Sleep disturbances among medical students: a global perspective. J Clin Sleep Med. 2015;11 (01):69-74. doi:10.5664/jcsm.4370

47. Sharma A, Dixit AM, Krishnappa K, Sharma R, Shukla S, Jain P. A comparative study of sleep habits among medical and non-medical students in Saifai, Etawah. Int J Community Med Public Health. 2018;5(9):3876. doi:10.18203/2394-6040.ijcmph20183420

48. McCabe SE, Teter CJ, Boyd CJ. Medical use, illicit use, and diversion of abusable prescription drugs. J Am Coll Health. 2006;54 (5):269-278. doi:10.3200/JACH.54.5.269-278

49. Amin DM, Elnadgi SA, Amer SA. Drug abuse in zagazig university students, Egypt: Crossectional study. Occupational Diseases and Environmental Medicine. 2019;7:37-39. doi:10.4236/ odem.2019.72004

50. Lemstra M, Bennett NR, Neudorf C, et al. A meta-analysis of marijuana and alcohol use by socio-economic status in adolescents aged 10-15 years. Can J Public Health. 2008;99(3):172-177. doi:10.1007/BF03405467

51. Fernández-Villa T, Molina AJ, Amezcua-Prieto C, et al. Drug use, family support and related factors in university students. A cross-sectional study based on the uniHcos project data. Gac Sanit. 2019;33:141-147. doi:10.1016/j.gaceta.2017.10.019

52. Martin MJ, Conger RD, Robins RW. Family stress processes and drug and alcohol use by Mexican American adolescents. Dev Psychol. 2019;55(1):170. doi:10.1037/dev0000629

\section{Publish your work in this journal}

Substance Abuse and Rehabilitation is an international, peerreviewed, open access journal publishing original research, case reports, editorials, reviews and commentaries on all areas of addiction and substance abuse and options for treatment and rehabilitation. The manuscript management system is completely online and includes a very quick and fair peer-review system. Visit http://www.dovepress. com/testimonials.php to read real quotes from published authors. 